\title{
STUDI PERBANDINGAN PENGGUNAAN TILE ADHESIVE DRY INTERIOR DENGAN MORTAR 1 PC : 3 PS TERHADAP DAYA REKAT UBIN KERAMIK \\ Drs. Dadang Suyadi M.Pd* dan Zaidin Ma'ruf Alwan, S.Pd
}

\begin{abstract}
Abstrak
The purpose of this research is for knowing and measuring whether the bond strength of tile adhesive dry interior more than the bond strength of $1 P C$ : 3 Ps mortar in tile construction. This research has been done in concrete laboratory of Civil Engineering Department of Indonesia University in year academy 2001-2002. The method that used in this research was experiment through the material test in laboratory. The research instrument that used is material bonding test, sand material test and blanco data. For data analyze was tested by average two tails (t-test), one tail test with $\alpha=$ 0,01. Based on the result of data analysis, $t_{\text {hitung }}=16,41$ and $t_{\text {tabel }}=2,47$ ( $t_{\text {hitung }}$ $\left.>t_{\text {tabel }}\right)$. In summary, this research conclution that the average value of bond strength tile adhesive dry interior (0,582 $\mathrm{MPa})$ more than the average value of bond strength 1 PC : 3 Ps mortar (0,392 MPa) in tile construction.
\end{abstract}

Kata Kunci : Daya rekat, Tile adhesive dry interior, Mortar

\section{Pendahuluan}

Seiring dengan perkembangan zaman manusia dituntut untuk lebih kreatif dan inovatif dalam segala bidang. Salah satu hasil inovasi manusia dalam bidang teknologi adalah tile adhesive dry interior yang dapat memudahkan manusia dalam melakukan pemasangan ubin keramik.

Daya rekat ubin keramik adalah kemampuan ubin keramik untuk direkat oleh mortar yang diuji berdasarkan kekuatan geser dan dinyatakan dalam Mpa atau $\mathrm{kg} / \mathrm{cm}^{2}$.

Tile adhesive dry interior adalah adukan siap pakai yang terbuat dari bahan dasar semen khusus untuk perekat keramik atau graniro penutup di dinding maupun untuk lantai pada daerah kering. Di Indonesia, tile adhesive dry interior masih belum banyak digunakan dikarenakan produk ini terbilang baru dan 
membutuhkan pengenalan ke masyarakat umum secara menyeluruh. Di samping itu juga dibutuhkan penelitian lanjutan guna mengetahui kualitas tile adhesive dry interior berdasarkan SNI 03-4877-1998. Oleh karena itu penulis tertarik untuk melakukan penelitian mengenai penggunaan tile adhesive dry interior sebagai bahan adukan untuk diukur sejauh mana daya rekat yang dihasilkan apabila dibandingkan dengan penggunaan mortar biasa berdasarkan SNI 03-4877-1998.

Tujuan penelitian ini adalah untuk mengetahui dan mengukur apakah penggunaan tile adhesive dry interior untuk pasangan ubin keramik menghasilkan daya rekat lebih dari pasangan ubin keramik yang menggunakan mortar dengan komposisi 1 PC : 3 Ps.

\section{Metode Penelitian}

Metode yang digunakan dalam penelitian ini adalah metode eksperimen melalui uji bahan di laboratorium.

Sedangkan rancangan penelitian ini digambarkan sebagai berikut :

\section{$\begin{array}{lllll}\text { Eksperimental satu } & \boldsymbol{E}_{\boldsymbol{A}} & \boldsymbol{X}_{\boldsymbol{A}} & --- & \boldsymbol{O}_{A}\end{array}$}

Eksperimental dua

Keterangan :

$\mathrm{E}_{\mathrm{A}}=$ Kelompok pekerjaan pasangan ubin keramik yang menggunakan tile adhesive dry interior.

$E_{B}=$ Kelompok pekerjaan pasangan ubin keramik yang menggunakan mortar $1 \mathrm{PC}: 3$ Ps.

$X_{A}=$ Perlakuan dengan menggunakan tile adhesive dry interior.

$\mathrm{X}_{\mathrm{B}}=$ Perlakuan dengan menggunakan mortar $1 \mathrm{PC}: 3$ Ps.

$\mathrm{O}_{\mathrm{A}}=$ Hasil pengujian daya rekat ubin keramik yang menggunakan tile adhesive dry interior.

$\mathrm{O}_{\mathrm{B}}=$ Hasil pengujian daya rekat ubin keramik yang menggunakan mortar $1 \mathrm{PC}: 3 \mathrm{Ps}$.

\section{Prosedur Penelitian}

Prosedur penelitian yang digunakan meliputi tiga tahap yaitu :

1. Pemeriksaan Bahan

a. Pasir

Studi Perbandingan Penggunaan Tile Adhesif Dry Interior dengan Mortar 1 PC : 3 Ps Terhadap Daya Rekat Ubin Keramik (Dadang Suyadi, Dosen Jurusan Teknik Sipil FTUNJ) 
- analisis kotoran organik dalam agregat halus

- Analisis saringan agregat halus

- Analisis kadar lumpur agregat halus

- Analisis spesific gravity dab absorpsi agregat halus.

b. Semen portland

Pada semen tidak dilakukan pemeriksaan karena semen yang digunakan adalah semen portland type I yang telah memenuhi standar SNI.

C. Air

Pada air tidak dilakukan pemeriksaan karena air yang digunakan adalah air dari PDAM Depok yang telah memenuhi persyaratan sebagai air minum.

d. Tile adhesive dry interior

Pada tile adhesive tidak dilakukan pemeriksaan karena telah melalui standar DIN 18555.

Pemilihan Benda Uji

Pemilihan benda uji ini dilakukan berdasarkan SNI 03-4877-1998 tentang cara uji daya rekat ubin keramik terhadap mortar.

a. Untuk ukuran sisi permukaan ubin $30 \mathrm{~mm}$ digunakan benda uji sebanyak 15 buah benda uji.

b. Benda uji harus dipilih atau diambil secara acak dari seluruh tanding.

c. Apabila benda uji mempunyai sisi tidak rata atau terdapat benjolan-benjolan atau tidak siku, maka benda uji tersebut harus diratakan atau dipotong sejauh 6,4 $\mathrm{mm}$ sehingga diperoleh sisi-sisi benda uji yang rata dan licin. Pemotongan tersebut harus dilakukan pada kondisi basah.

d. Benda uji yang telah dipotong kemudian dicuci dengan air bersih dan dikeringkan dalam oven pengering pada suhu $107 \pm 5^{0}$ selama 4 jam.

e. Benda uji kemudian didinginkan hingga mencapai suhu kamar dan dibersihkan dari segala kotoran dan debu yang melekat di permukaan yang akan direkat.

2. Cara Kerja Pembuatan dan Pengujian Benda Uji

MENARA, JURNAL TEKNIK SIPIL VOL. I, NO. 1, JANUARI $2006: 48-56$ 
Cara kerja dan pembuatan benda uji ini dilakukan berdasarkan SNI 03-4877-1998 tentang cara uji daya rekat ubin keramik terhadap mortar.

a. Oleskan minyak pada permukaan dalam cetakan (lihat gambar 1 hal.7) untuk mempermudah pelepasan benda uji setelah selesai disiapkan. Sebagai perekat ubin digunakan mortar tile adhesive dry interior dan mortar $1 \mathrm{PC}: 3$ Ps.

b. Ratakan permukaan mortar dengan cara membuat sisi lurus, sisakan pada cetakan yang berlawanan, buang kelebihan mortarnya. Diamkan mortar dalam waktu 1 - 1,5 jam setelah penyiapan ini. Lapisi permukaan belakang benda uji dengan adonan setebal 0,8-1,6 mm yang terdiri dari 1 bagian semen dan 0,36 bagian air bersih.

c. Tempelkan benda uji di atas lapisan mortar dengan salah satu sisi lurusnya di tonjolkan sejauh 6,4 mm memanjang dan sejajar dengan lapisan mortar. Usahakan benda uji berada di bagian tengah.

d. Apabila bentuk ubin tidak bujur sangkar, letakkan sedemikian rupa sehingga sisi memanjangnya berada pada posisi tegak lurus selama pembebanan.

e. Apabila bagian belakang ubin mempunyai alur, letakkan sedemikian rupa sehingga arah alur sejajar dengan arah pembebanan.

f. Atur posisi ubin, tekan dengan kuat sehingga seluruh permukaan palisan pengikat menempel dengan baik terhadap lapisan mortar, kemudian bersihkan kelebihan adukan semen yang berada disekitar sisi ubin.

g. Biarkan benda uji dalam kondisi lembab selama 16-24 jam dan ditutup dengan kain basah dan lapisan plastik.

h. Ambil benda uji dalam cetakan dan biarkan selama 6 hari pada suhu kamar dan kelembaban minimum $90 \%$.

i. Segera letakkan benda uji kedalam pegangan penjepit (lihat gambar 2 hal. 7). Kencangkan rangkaian benda uji tersebut dengan klem terhadap penjepit dan pasang rangkaian tersebut pada mesin penekan.

j. Bebani satu benda uji sampai rekatannya terlepas. Lakukan cara yang sama terhadap benda uji yang lain.

Perhitungan kekuatan daya rekat benda uji dihitung berdasarkan rumus : $T=P / A$

Dimana :

Studi Perbandingan Penggunaan Tile Adhesif Dry Interior dengan Mortar 1 PC : 3 Ps Terhadap Daya Rekat Ubin Keramik (Dadang Suyadi, Dosen Jurusan Teknik Sipil FTUNJ) 
$\mathrm{T}=$ Kekuatan daya rekat ubin keramik $(\mathrm{MPa})$

$\mathrm{P}=$ Beban maksimum $(\mathrm{N})$

$A=$ Luas permukaan ubin yang direkat $\left(\mathrm{mm}^{2}\right)$.

Keterangan :

$1 \mathrm{MPa}=1 \mathrm{~N} / \mathrm{mm}^{2}=10,2 \mathrm{kgf} / \mathrm{cm}^{2}$ dan $1 \mathrm{KN}=102 \mathrm{kgf}$.
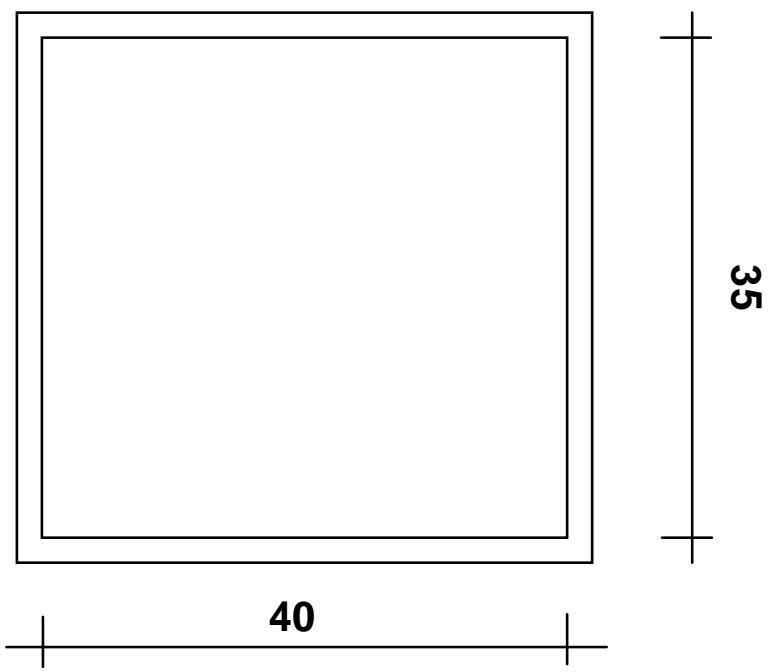

Gambar 1. Cetakan Benda Uji

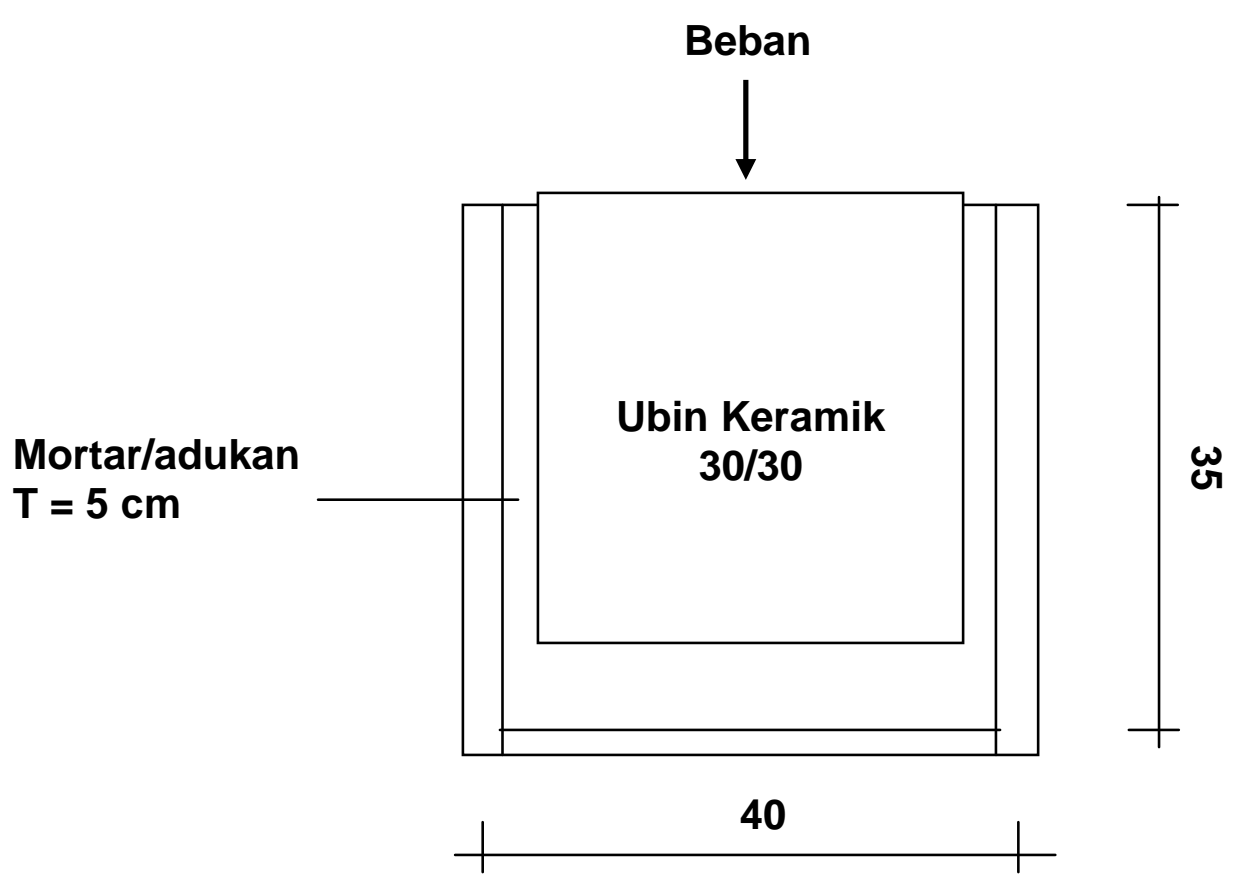

Gambar 2. Penjepit Benda Uji

MENARA, JURNAL TEKNIK SIPIL VOL. I, NO. 1, JANUARI $2006:$ 48-56 


\section{Hasil Penelitian}

Percobaan pengujian yang dilakukan meliputi pengujian analisis saringan agregat halus, analisis kotoran organik dalam agregat halus, analisis kadar lumpur agregat halus dan analisis spesific gravity dan absorpsi agregat halus, dan pengujian daya rekat ubin keramik. Hasil pengujian daya rekat ubin keramik dapat dilihat sebagai berikut :

Tabel 1. Data Hasil Pengujian Daya Rekat Ubin Keramik

\begin{tabular}{|c|c|c|}
\hline \multirow[b]{2}{*}{ No } & \multicolumn{2}{|c|}{ Daya Rekat Ubin Keramik } \\
\hline & $\begin{array}{l}\text { Tile Adhesive Dry Interior } \\
\qquad(\mathrm{MPa})\end{array}$ & Mortar 1 PC : 3 Ps (MPa) \\
\hline 1 & 0,608 & 0,375 \\
\hline 2 & 0,591 & 0,358 \\
\hline 3 & 0,545 & 0,386 \\
\hline 4 & 0.562 & 0,375 \\
\hline 5 & 0,534 & 0,409 \\
\hline 6 & 0,608 & 0,409 \\
\hline 7 & 0,613 & 0,386 \\
\hline 8 & 0,540 & 0,432 \\
\hline 9 & 0,625 & 0,449 \\
\hline 10 & 0,585 & 0,403 \\
\hline 11 & 0,613 & 0,409 \\
\hline 12 & 0,562 & 0,329 \\
\hline 13 & 0,545 & 0,358 \\
\hline 14 & 0,591 & 0,432 \\
\hline 15 & 0,608 & 0,375 \\
\hline
\end{tabular}

Studi Perbandingan Penggunaan Tile Adhesif Dry Interior dengan Mortar 1 PC : 3 Ps Terhadap Daya Rekat Ubin Keramik (Dadang Suyadi, Dosen Jurusan Teknik Sipil FTUNJ) 


\begin{tabular}{|c|c|c|}
\hline $\mathrm{X}$ & 0,582 & 0,392 \\
\hline
\end{tabular}

\section{Uji Normalitas.}

Analisa yang digunakan untuk menguji normalitas data adalah uji Lilliefors. Data yang dianalisa adalah data nilai daya rekat ubin keramik.

1. Uji normalitas data daya rekat ubin keramik yang menggunakan tile adhesive dry interior.

Hasil pengujian normalitas dari data nilai daya rekat ubin keramik yang menggunakan tile adhesive dry interior menghasilkan $L_{\circ}=0,1496$, pada taraf nyata $(\alpha)=0,01$ diperoleh nilai $L_{\text {Tabel }}=0,257$, dengan kriteria pengujian apabila $L_{\circ}$ $<\mathrm{L}_{\text {Tabel }}$ maka data berdistribusi normal, dengan demikian dapat disimpulkan bahwa populasi kelompok berdistribusi normal.

2. Uji normalitas data daya rekat ubin keramik yang menggunakan mortar $1 \mathrm{PC}$ : 3 Ps

Hasil pengujian normalitas dari data nilai daya rekat ubin keramik yang menggunakan mortar 1 PC : 3 Ps menghasilkan $L_{0}=0,1087$, pada taraf nyata $(\alpha)$ $=0,01$ diperoleh nilai $L_{\text {Tabel }}=0,257$, dengan kriteria pengujian apabila $L_{o}<L_{\text {Tabel }}$ maka data berdistribusi normal, dengan demikian dapat disimpulkan bahwa populasi kelompok berdistribusi normal.

Uji Homogenitas

Analisis statistik yang digunakan untuk menguji homogenitas adalah uji kesamaan dua varian (uji F). Dari perhitungan diperoleh $F_{\text {Hitung }}=0,933$, dengan taraf nyata $(\alpha)=0,01$ dari daftar distribusi $F$ dengan $\mathrm{dk}$ pembilang $=14 \mathrm{dan} \mathrm{dk}$ penyebut $=14$ didapat $F_{0,01(14,14)}=2,48$ dan $F_{0,99(14,14)}=0,270$ sehingga nilai $F$ berada diantara $F_{0,99(14,14)}<F_{\text {Hitung }}<F_{0,01(14,14)}$, maka dapat disimpulkan varian dari kedua kelompok adalah homogen.

\section{Pengujian Hipotesis}

MENARA, JURNAL TEKNIK SIPIL VOL. I, NO. 1, JANUARI $2006: 48-56$ 
Pengujian nilai daya rekat ubin keramik yang menggunakan tile adhesive dry interior dan mortar 1 PC : 3 Ps, hipotesis nol $\left(\mathrm{H}_{0}\right)$ sebagai berikut : tidak ada perbedaan yang signifikan dari penggunaan tile adhesive dry interior dan mortar 1 PC : 3 Ps terhadap nilai daya rekat ubin keramik.

Untuk membuktikan hasil pengujian maka data di analisa dengan menggunakan uji kesamaan dua rata-rata (uji t), uji satu pihak, pihak kanan dengan taraf signifikan $(\alpha)=0,01$ dimana $t_{\text {Hitung }}=16,41$ dan $t_{\text {Tabel }}=2,47$ berarti $t_{H i t u n g}>t_{\text {Tabel }}$ maka $H_{o}$ ditolak, sehingga ada perbedaan yang siginifikan dari penggunaan tile adhesive dry interior dengan mortar 1 PC : 3 Ps terhadap nilai daya rekat ubin keramik.

\section{Pembahasan Hasil Penelitian}

\section{Analisis Pelaksanaan Pengujian}

Analisis pelaksanaan pengujian baik yang menggunakan tile adhesive dry interior maupun yang menggunakan mortar 1 PC : 3 Ps adalah sebagai berikut; ketika seluruh benda uji ditekan satu persatu, benda uji jatuh kebawah dengan semen sebagai perantara perekatan menempel pada benda uji. Dengan demikian dapat disimpulkan bahwa daya rekat yang terjadi adalah daya rekat ubin keramik terhadap adukan/mortar.

\section{Analisis Hasil Penelitian}

Berdasarkan hasil penelitian yang dilakukan diperoleh hasil rata-rata nilai daya rekat ubin keramik yang menggunakan mortar tile adhesive dry interior lebih dari hasil rata-rata nilai daya rekat pasangan ubin keramik yang menggunakan mortar dengan komposisi 1 PC : 3 Ps. Perbedaan ini terjadi dikarenakan pengaruh faktor jenis bahan baku dan komposisi bahan baku yang digunakan pada kedua jenis mortar.

\section{Kesimpulan Dan Saran}

\section{Kesimpulan}

Kesimpulan yang dapat ditarik dari hipotesis yang telah diuji adalah nilai ratarata daya rekat ubin keramik yang menggunakan tile adhesive dry interior 
sebesar 0,582 MPa secara signifikan lebih dari nilai rata-rata daya rekat ubin keramik yang menggunakan mortar dengan komposisi 1 PC : 3 Ps yang hanya sebesar $0,392 \mathrm{MPa}$.

\section{Saran}

Berdasarkan hasil penelitian dan kesimpulan di atas, maka penulis ingin memberikan saran-saran sebagai berikut :

a. Diperlukan penelitian lanjutan tentang tile adhesive dry interior sebagai mortar alternatif dalam pekerjaan pasangan ubin keramik.

b. Hasil penelitian ini sekaligus membuktikan bahwa tile adhesive dry interior dapat digunakan sebagai mortar alternatif dalam pekerjaan pasangan ubin keramik.

\section{Daftar Pustaka}

Frick, Heinz, Ilmu Konstruksi Bangunan I, Yogyakarta : Panerbit Kanisius,1980.

Frick Heinz dan Koesmartadi CH, IImu Bahan Bangunan (Eksploitasi,Pembuatan, Pengunaan dan Pembuangan, Yogyakarta : Penerbit Kanisius, 1977.

Kasma dan Maman Sulaiman, Keramik Sebagai Bahan Bangunan, Bandung: Dirjen Cipta Karya-Dept. PU dan Tenaga Listrik.

K. Gieck, Kumpulan Rumus Teknik, Jakarta : PT. Pradnya Paramita, 1992

Panitia Dep. PUTL-UGM, Istilah Teknik Bangunan Gedung Inggris-Indonesia Bagian Kesatu A - L, Badan Penerbit PU, 1977.

Panitia Dep. PUTL-UGM, Istilah Teknik Bangunan Gedung Inggris-Indonesia Bagian Kedua M-L, Badan Penerbit PU, 1977.

Subarkah, Imam. Konstruksi Bangunan Gedung, Bandung : Penerbit Idea Dharma, 1998.

SKSNI T-15-1991-03, Tata Cara Pembuatan Rencana Campuran Beton Normal, Jakarta : Departemen Pekerjaan Umum.

SNI 03-4877-1998, Cara Uji Daya Rekat Ubin Keramik Terhadap Mortar, Jakarta : Badan Standarisasi Nasional.

SKSNI S-002-1994-03, Spesifikasi Agregat Halus Untuk Pekerjaan Adukan dan Plesteran Dengan Bahan Dasar Semen, Jakarta : Departemen Pekerjaan Umum.

Sudjana, Metode Statistika, Bandung : Tarsito, 1992.

Team Technical Support Engineer, Buku Panduan Pengetahuan Data dan Produk, PT. Duta Mortar Sejati, 2000

MENARA, JURNAL TEKNIK SIPIL VOL. I, NO. 1, JANUARI $2006: 48-56$ 
Studi Perbandingan Penggunaan Tile Adhesif Dry Interior dengan Mortar 1 PC : 3 Ps Terhadap Daya Rekat Ubin Keramik (Dadang Suyadi, Dosen Jurusan Teknik Sipil FTUNJ) 